\title{
Budaya Pecinta Kopi dan Gaya Hidup Urban Kedai Kopi di Surabaya: Analisis Visual Semiotika Spasial
}

\author{
Abduh Rafif Taufani \\ Departemen Ilmu Komunikasi, Universitas Airlangga, Jalan Dharmawangsa Dalam no. 4-6, \\ Indonesia.Email:abduhrafiftaufani@gmail.com
}

\begin{abstract}
A B S T R A C T
This research are focused on cultural identity and urban lifestyle that being representated throu symbols on coffeeshops in Surabaya. The research are conducted using vernacular semiotics or better called as spatial semiotic analysis. The researcher are interested due to current trends of third-wave coffeshops and how they identify themselves as a coffee lovers, also how third-wave customers put meaning in urban lifestyle in general throu themselves, visual gimmick, and interior design of the coffeeshops. Vernacular Semiotic are chosen as an analytic instruments because the visual elements surrounding the coffeshops and their customers are treated as visual text. The meaning behind coffee-drinkin activity are actively produced by the urban dwellers that habitate the spatial space of the coffeeshops. This research conclude that urban dwellers/customers are more drawn into the meaning throu visual elements to go to coffeeshops rather than the actual beverages. Therefore urban dwellers are also consuming the meaning behind every activity they are doing. The consumed meaning is either produced by the urban dwellers or the coffeshop itself.
\end{abstract}

Keywords: Cultural Identity; Lifestyle; Urban Community; Vernacular Semiotics

\section{A B S T R A C T}

Penelitian ini fokus pada identitas budaya pecinta kopi dan gaya hidup urban yang direpresentasikan melalui simbol-simbol yang ada pada kedai kopi di Surabaya menggunakan analisis semiotika spasial, atau vernacular semiotics. Peneliti tertarik dengan fenomena munculnya konsumen kopi gelombang ketiga dan identitasnya sebagai pecinta kopi. Juga bagaimana konsumen kopi gelombang ketiga memaknai gaya hidup urban dalam kedai kopi di Surabaya lewat pengunjung, gimmick, dan desain interior kedai kopi. Vernacular Semiotic digunakan sebagai pisau analisis karena peneliti membaca bahwa elemen-elemen visual dalam kedai kopi sebagai teks yang di dalamnya mengandung makna.. Pemaknaan ini sengaja dibangun oleh komunitas pecinta kopi sebagai kaum urban yang menempati ruang spasial lalu membangun identitas budaya dan gaya hidup mereka. Hasil akhirnya, penelitian ini menemukan fakta bahwa banyak pelanggan kedai kopi di daerah urban tidak dating ke kedai atas minumannya saja, melainkan mereka juga mengonsumsi makna dari aktivitas meminum kopi dan juga kedai kopi yang disematkan lewat berbagai elemen visual baik yang mereka produksi secara sengaja ataupun tidak.

Kata kunci: Identitas budaya; Gaya hidup; Masyarakat urban; Vernacular semiotics

\section{A. PENDAHULUAN}

Penelitian ini fokus pada identitas budaya pecinta kopi yang ada pada kedai kopi di Surabaya. Peneliti akan melihat dan mengkaji beberapa komponen mulai dari pelanggan (konsumen), desain bar, slogan, dan bahasa dalam kedai kopi di Surabaya sebagai bentuk-bentuk dari identitas budaya pecinta kopi. Lalu akan dianalisis lebih jauh sebagai sebuah bentuk (form) komunikasi dan sistem makna dari tanda-tanda (signs) dan simbol (symbols) yang melekat pada konsumen, desain, slogan, dan bahasa yang ada di dalam ruang (space) kedai kopi sebagai representasi-representasi masyarakat kota. Kedai kopi di Surabaya yang menjadi objek penelitian adalah Rumah Rendjana, Start with Coffee, serta Sequence. Ketiga kedai kopi ini termasuk dalam kedai kopi third wave. 
Metode penelitian yang digunakan adalah analisis semiotik spasial menggunakan pendekatan kualitatif. Peneliti menggunakan metode tersebut karena fokus pada pembuatan makna atas teksteks yang ada (visual texts) dalam kedai kopi (spasial) yang diartikulasikan sebagai pemaknaan atas identitas budaya pecinta kopi dan gaya hidup urban kedai kopi Surabaya. Teks-teks visual tadi akan dikumpulkan oleh peneliti dalam bentuk foto (photographic survey) dan dimaknai oleh peneliti sendiri sesuai dengan penelitian visual yang melihat objek visual dari site of self (Ida, 2014).

Kedai kopi dipilih karena keberadaannya akhir-akhir ini banyak bermunculan di Surabaya. Tercatat pada tahun 2018 ketiga kedai kopi tersebut baru saja membuka bisnisnya. Peneliti akan mengungkap apa saja identitas pecinta kopi yang ada dalam ketiga kedai kopi tersebut. Masingmasing kedai kopi menawarkan konsep yang serupa dan erat dengan para pecinta kopi. Asumsi dasar peneliti adalah pada ketiga kedai kopi tersebut muncul beragam identitas komunitas pecinta kopi baik dari kedai itu sendiri maupun individu-individu di dalamnya. Namun, kedai kopi yang akan diteliti hanya yang termasuk dalam kedai kopi gelombang ketiga.

Budaya kopi sendiri erat kaitannya dengan budaya Indonesia. Sejak jaman penejajahan hingga kini menjadi budaya yang terasa lokal. Artinya tiap-tiap tempat dan daerah mempunyai ciri khasnya sendiri yang tidak dapat disamakan begitu saja. Peneliti melihat budaya kopi yang berada di wilayah urban, kota Surabaya. Khususnya pada budaya kopi kedai-kedai third wave/era. Third era adalah era dimana konsumen kopi jauh lebih kritis daripada sebelumnya dan era di mana kopi spesialti diperkenalkan. Pada era ini muncul budaya ngopi yang jauh berbeda dengan era-era sebelumnya. Konsumen mulai kritis mempertanyakan asal-usul biji kopinya, kualitas biji kopi, hingga cara mengolah dan penyajiannya. Muncul pula beberapa istilah yang digunakan untuk menilai kualitas kopi seperti aftertaste, body, acidity, bitterness, sweetness sampai ke aroma dari seduhan kopi tersebut (Hindrawan, 2018).

Di Surabaya juga muncul berbagai kedai kopi sebagai respon atas munculnya konsumen kopi gelombang ketiga. Tercatat peningkatan kedai kopi di Surabaya dalam kurun waktu satu bulan pada tahun 2016, ada dua belas kedai kopi spesialti yang buka di Surabaya dan terbukti ramai pengunjung. Hal itu juga sejalan dengan peningkatan konsumen kopi yang mencapai angka 23\% pada tahun 2017 dan terus meningkat (Eleonora, 2017). Meningkatnya konsumen kopi di Surabaya menjadikan pasar kedai kopi penuh persaingan. Seluruh kedai kopi berusaha menjajarkan keunikannya masing-masing lewat konsep kedai yang berbeda-beda. Namun, seringkali konsep kedai kopi gelombang ketiga tidak selalu terlihat.

\section{B. METODE}

Penelitian ini menggunakan metode vernacular semiotics yang akan menanggap ruang spasial dan pelanggan kedai kopi sebagai teks-teks visual yang dapat diberi pemaknaan. Vernacular semiotic sendiri adalah metode semiotika spasial yang dikembangkan khusus untuk membaca masyarakat perkotaan. (Krase \& Shortell, 2011). Metode ini menggunakan photographic survey dan observasi sebagai alat analisisnya. Peneliti nantinya akan datang ke ketiga kedai kopi secara berkala tiap minggu, mulai hari Jumat-Minggu, sejak jam buka hingga tutup. Peneliti akan memotret suasana dalam kedai kopi, tanpa punya objek fokus utama dan diambil lewat kacamata pelanggan. Artinya foto akan diambil selagi duduk di meja pelanggan dan melihat visual apa saja yang akan terpapar lewat meja pelanggan. Tipe penelitian ini adalah eksploratif, digunakan karena peneliti akan menggambarkan fenomena sosial dan menjelaskan 
bagaiman hal itu bisa terjadi. Ada dua pendekatan yang dilakukan oleh peneliti yaitu observasi dan melihat perilaku pelanggan dalam kedai kopi dan berikutnya adalah photographic survey. Subjek penelitian ini adalah pengunjung kedai kopi (customer), desain interior café di kedai kopi, bahasa yang digunakan (phatic signs), serta gimmick visual seperti tulisan di dinding, penempatan logo, bentuk bar hingga slogan kedai kopi. Peneliti akan menggunakan data primer dari hasil observasi dan photographic survey serta menggunakan data sekunder lewat studi pustaka dan internet.

Dalam menganalisa, peneliti menggunakan urutan tahap analisis. Pertama adalah penyeleksian data-data yang telah dikumpulkan dan dipilah mana yang relevan dengan fokus permasalahan penelitian. Kedua, peneliti akan melakukan klasifikasi data sesuai dengan tiap kedai kopi yang relevan untuk menjawab rumusan masalah terkait makna identitas budaya pecinta kopi. Ketiga peneliti akan melakukan intepretasi data menggunakan vernacular semiotics. Terakhir akan ditarik kesimpulan dari hasil intepretasi tersebut.

\section{HASIL DAN PEMBAHASAN}

Peneliti menemukan fakta bahwa dalam ketiga kedai kopi menawarkan pemaknaan budaya yan berbeda-beda. Tiap budaya tersebut erat kaitannya dengan bagaimana pelanggan memaknai aktivitas meminum kopi yang mereka anggap baik dan benar.

\section{Kedai Kopi Start with Coffee : Kopi dan Mahasiswa}

Pertama adalah kedai kopi Start with Coffee. Letak kedai ini berada dalam Kawasan kampus yang dipenuhi oleh berbagai warga akademis dari dosen hingga mahasiswa. Di sini makna budaya meminum kopi erat pula dengan aktivitas khas akademisi. Yaitu, meminum kopi sambal mendengarkan tugas, atau bercanda gurau sesame mahasiswa lainnya. Di sini kedai kopi dianggap sebagai tempat berkumpul yang dapat menunjang kebutuhan mahasiswa atau akademisi untuk melakukan kerja kelompok atau diskusi. Hal itu terlihat lewat berbagai macam tanda visual seperti tatanan meja, pakaian pelanggan hingga slogan kedai kopi itu sendiri.

Meja yang digunakan oleh Start with Coffee adalah meja panjang dengan kursi yang panjang pula, sehingga memungkinkan mahasiswa dan akademisi lainnya untuk melakukan diskusi Selain itu, kedai kopi mempunyai ciri khas dalam desain ruangnya. Sesungguhnya kedua desain baik dari kedai kopi dan warung kopi mempunyai persamaaan fungsi, yaitu sebagai tempat berkumpul dan bersantai menikmati kopi. Namun sesuai dengan ciri khas pelanggannya yang membedakan adalah dalam kedai kopi gelombang ketiga, ruang kedai kopi juga berfungsi sebagai wadah untuk memperkenalkan kopi-kopi spesialti dan memberikan wawasan kepada pelanggan terkait kopi dan olahannya. Hal itu dapat dilihat lewat peletakan bar yang berada didepan kedai.

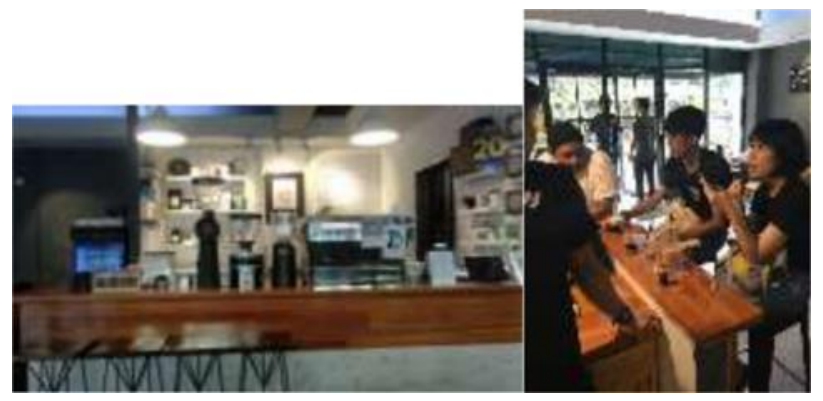

Sumber: Dokumen Pribadi Penulis 


\section{Gambar 1. Letak coffee bar pada kedai kopi Start with Coffee}

Letak bar yang ada didepan dimanfaatkan oleh mahasiswa untuk berdiskusi soal hasil olahan kopi hingga diskusi kelompok. Konsumsi kafein dan kopi sebelumnya telah diteliti oleh Nicole Olsen. Lewat penelitiannya, mengonsumsi produk dengan kafein adalah kegiatan seharisehari mahasiswa di Amerika Serikat. Mahasiswa menganggap bahwa kopi dan produk kafein lainnya sangat berguna untuk membuat mereka terjaga dan lebih efektif dalam mengerjakan tugastugas perkuliahan (Olsen, 2013, h.17). Hal serupa juga terjadi di Start with Coffee dimana mayoritas pelanggannya adalah mahasiswa.

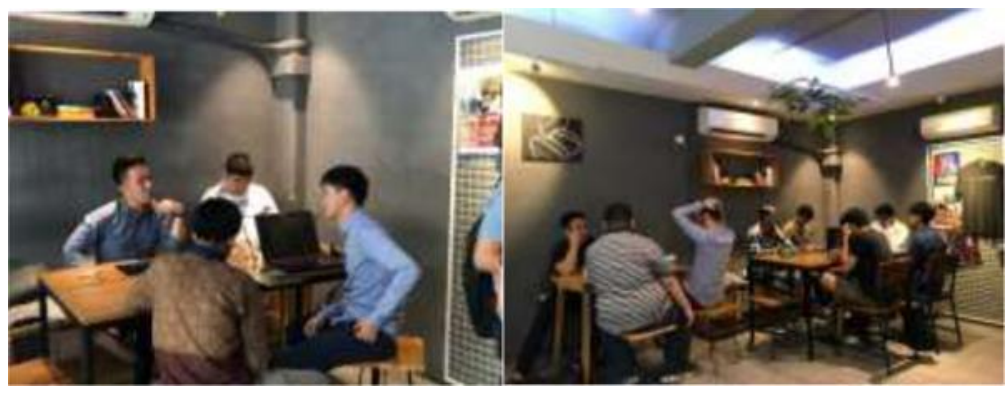

Sumber: Dokumen Pribadi Penulis

Gambar 2. Pelanggan di dalam kedai Start with Coffee

Kedai kopi ini berada di pinggir jalan dan berlokasi di area kampus. Secara referensial arsitektur bangunan dan ruang di dalam dibuat secara sederhana atau minimalis, layaknya sebuah kantin kopi di kampus. Interior di tata secara lugas menunjukkan kantin kopi ala mahasiswa. Dengan model kursi bar di depan dapur kopi, dan meja panjang yang bisa digunakan untuk duduk beberapa orang. Aspek individualitas agaknya tidak ditampakkan dalam desain interior dan penataan furniture di dalam kedai kopi. Dari model desain seperti ini, makna referensial atau ekspresif semakin jelas bahwa kedai kopi ini menjadi ruang nongkrong, berinteraksi, dan melakukan diskusi-diskusi kelompok beberapa mahasiswa yang datang mengunjunginya. Terlihat pula dari menu yang disediakan ala kantin, dan juga pakaian casual yang dikenakan ala mahasiswa kampus di Surabaya. Selain itu warna gelap dinding tembok menjadi penguat kesan serius sebagai ruang untuk membicarakan hal akademik, bukan hanya sebagai ruang minum kopi seperti pada kedai-kedai kopi komersial kaum middle class kota. Mahasiswa secara aktif menggunakan fasilitas yang telah disediakan ruang kedai kopi untuk menunjang kegiatan mereka. Terlebih lagi, lewat aktivitas pengunjungnya dan bagaimana kedai kopi mendukung hal itu lewat fasilitas yang ia sediakan justru membuat identitas kultural baru dalam kedai. Identitas baru ini tentunya sesuai dengan slogan Start with Coffee yang menyematkan kata \#ngopidikampus dimana aktivitas kopi disandingkan sebagai pelengkap aktivitas akademisi. Kesan anak muda juga hadir lewat tanda visual poster-poster komunitas yang ada di Start with Coffee. 


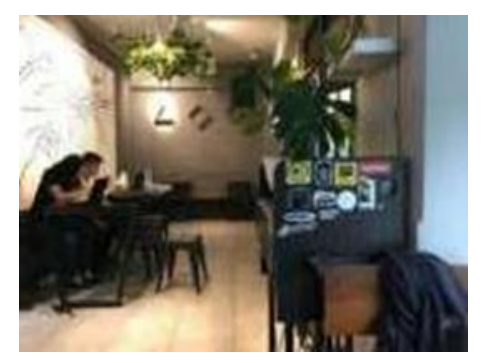

Sumber: Dokumen Pribadi Penulis

\section{Gambar 3. Stiker Komunitas di Start with Coffee}

Stiker komunitas yang ditempel dalam kedai kopi adalah tanda ekspresif yang memunculkan kepemilikan atas tempat yang mereka singgahi. Membangun hubungan antara siapapun yang ada di dalam kedai kopi. Stiker ini juga menjadi rujukan bahwa beberapa komunitas tersebut pernah atau sering bersinggah di satu tempat yang sama. Hal ini juga membantu pelanggan untuk membangun place attachment (Waxman, 2004). Dimana ruang urban mempunyai ikatan secara fisik dan sosial. Fisik dalam artian stiker tersebut ditempel dengan sengaja sebagai tanda ekspresif, sementara lewat tanda fisik tersebut dapat ditarik kesimpulan bahwa interaksi sosial khusus pernah berlangsung antara komunitas dan kedai kopi itu sendiri. Makna simbolik ini menurut Kraes dan Shortell dapat terlihat lewat tanda-tanda ekspresif yang sengaja dimaknai berbeda oleh para pelakunya untuk mengukuhkan identitas mereka. Komunitas-komunitas yang menempel stikernya mayoritas tidak selalu berkutat seputar kedai kopi saja. Melainkan gabungan dari berbagai komunitas anak muda yang singgah ke Start with Coffee. Tanda ekspresif adalah 'The embedded meanings that facilitate social relations' (Krase \& Shortell, 2013). Dengan berbagai jenis simbol yang khusus, Kedai Start with Coffee menandakan siapa mereka kepada para pelanggan dan hal itu mempengaruhi pelanggan untuk memaknainya kembali. Slogan utama Start with Coffee adalah \#ngopidikampus yang dimaknai oleh para pelanggannya sebagai tempat dimana mahasiswa menghabiskan waktu luang atau sekaligus mengerjakan pekerjaan dari kampus mereka. Tanda-tanda ekspresif seperti logo dan slogan memfasilitasi ruang interaksi yang khusus di Start with Coffee dan juga membatasi ruang spasial mereka.

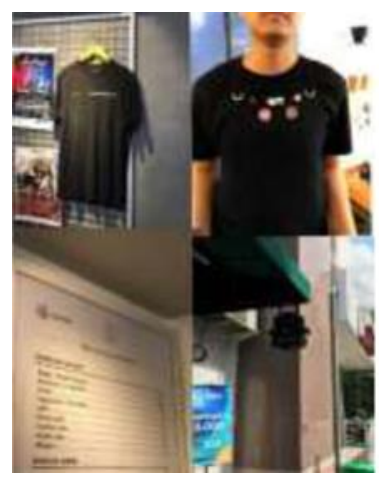

Sumber: Dokumen Pribadi Penulis

Gambar 4. Logo Start with Coffee di Berbagai Tempat 
Dengan memberikan logo serta slogan di tiap sudut kedai maka Start with Coffee telah mendeklarasikan kepemilikan mereka atas suatu ruang vernacular. Tanda ekspresif seperti logo selain menjadi penanda batas tempat juga menjadikan ruang spasial itu mempunyai identitas sendiri. Identitas tadi tidak semata-mata hanya tercipta lewat penempatan logo. Tapi bagaimana logo tadi menentukan cara seseorang berperilaku sesuai dengan ruang yang direferensikan oleh logo tersebut. 'These signs are artifacts of ordinary social interaction that become markers of settlement space. They are the indicators that we are 'at home' in our neighborhood' (Krase \& Shortell, 2011)

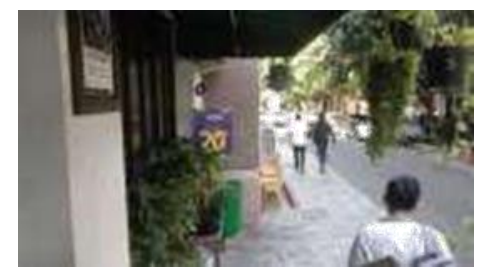

Sumber: Dokumen Pribadi Penulis

\section{Gambar 5. Lingkungan di Luar dan di Dalam Kedai Start with Coffee}

Dalam jajaran kedai juga dapat terlihat berbagai pilihan untuk membayar menggunakan alternatif $e$-wallet dimana lebih mudah diketahui oleh orang perkotaan yang sudah lama tinggal di Surabaya. Pada bagian depan kedai logo Start with Coffee plakat pembayaran e-wallet yang berdampingan. Hal ini adalah tanda phatic yang menyuarakan pelanggan seperti apa yang hadir di kedai tersebut. Keberadaan plakat $e$-wallet juga menjadi tanda visual bahwa pelanggan adalah masyarakat kota yang sadar akan teknologi dan kebaruannya. Tanda-tanda ini pula menyuarakan bagaimana hidup di perkotaan memfasilitasi perbedaan kelas. Lewat pemberian tanda demikian, perkotaan melanggengkan prosesnya perbedaan (heterogenitas) dalam masyarakat kota. Perbedaan ini mengacu pada bagaimana ruang spasial sering ditandai dengan berbagai fasilitas antara yang modern dan tidak lewat ekspresi visual. Hal itu sejalan dengan pemikiran Peter Marcuse 'There is overwhelming empirical evidence showing that rather than facilitating difference, contemporary cities are actually fostering, and giving visual expression to, greater social, cultural and economic inequality, leading, in particular, to the development of enclaves of homogeneit' (Stevenson, 2003, h. 44).

\section{Kedai Kopi Sequence : 'Slow Lazy Bar' dan 'We Brew Speciality Coffee'}

Terletak tidak terlalu jauh dengan Rumah Rendjana yaitu beralamat di Jl. Ngagel Jaya Barat No.79, Pucang Sewu, Kecamatan Gubeng, Surabaya namun mempunyai perbedaan signifikan dari kedua kedai kopi lainnya. Sequence merupakan kedai kopi dengan pengunjung yang relatif sedikit. Rata-rata pengunjung di kedai kopi ini didominasi oleh para pekerja daripada anak muda. Sequence sendiri berdampingan tempat dengan sebuah barbershop dan juga restoran Retro Teras Kuliner. Seringkali Sequence justru dijadikan titik kumpul rapat dan makan siang para pekerja pada siang hari. Hal ini dikarenakan lokasinya yang bersebelahan dengan berbagai kantor. Sementara saat malam, didominasi oleh anak muda. Desain, perpaduan warna, dan interior akan mempengaruhi persepsi dan aktivitas manusia di dalamnya. Menurut penelitian oleh Nancy Kwallek warna putih akan membuat kesan luas dan lebar (Öztürk et al., 2012). Karena tata ruang Sequence memang tidak lebih luas dari kedua kedai kopi sebelumnya maka perpaduan warna putih 
dan hitam menjadi alternatif. Desain ruang sequence juga disusun selayaknya persegi panjang dan bukan kotak. Hal ini akan memberikan kesan luas bagi pelanggan yang datang ke kedai. Menurut Waxman 'rooms that were more rectangular were perceived as larger than rooms with configurations closer to a square' (Waxman, 2004, h. 11).

Kursi-kursi di kedai kopi sequence menyediakan kursi layaknya tempat makanan pinggir jalan dengan tatanan kursi untuk perorangan, tetapi dengan desain meja panjang yang menyatu. Desain seperti ini tidak memberikan sekat antara pelanggan kedai kopi, melainkan memberikan ruang bagi para pelanggan untuk saling berinteraksi. Tatanan kursi seperti ini adalah tanda ekspresif dari kedai kopi yang ingin memperlihatkan bahwa mereka adalah kedai kopi dengan tema Slow Lazy Bar. Dimana mereka mengamini bahwa pelanggan yang datang ke sequence tidak terlalu banyak maka kursi yang disediakan tidak banyak pula.

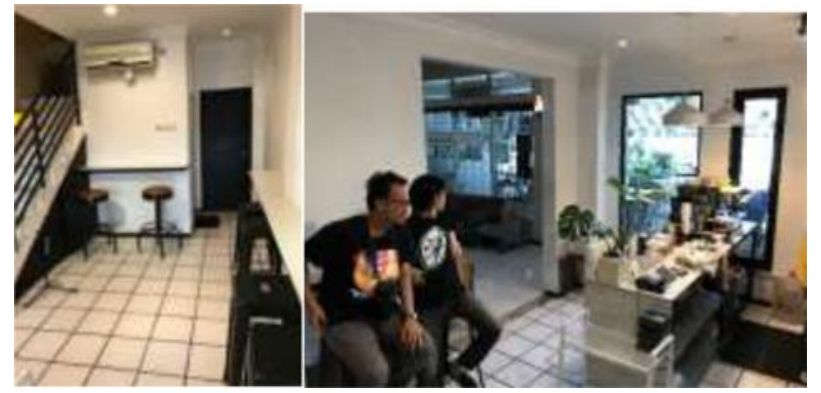

Sumber: Dokumen Pribadi Penulis

\section{Gambar 6. Pelanggan Sequence Menunggu Pesanan Mereka}

Kesan santai dalam kedai dikukuhkan lewat desain ruang mereka yang memberikan banyak tempat duduk bersantai seperti sofa, dan kursi santai. Pengunjung seringkali menghabiskan waktu yang lama di kedua tempat ini. Desain interior ini adalah salah satu contoh ekspresif dimana kedai kopi berusaha memperlihatkan diri mereka sebagai kedai kopi third wave yang menyediakan kopi untuk dinikmati dengan bersenang-senang atau leisure.

Pelanggan kedai Sequence memanfaatkan waktu luang mereka dapat terlihat lewat bagaimana mereka menggunakan tempat tertentu untuk bercanda gurau dan selalu ramai di tempat tersebut. Pemafaatan leisure dalam ruang "third place" mempunyai dampak signifikan pada keberlangsungan hidup seseorang. Mengingat bahwa "third place" sendiri adalah "it is relatively free, accompanied by a minimum of constraints; satisfaction are primarily intrinsic; and (3) it is playful, in the sense of being self-contained, having to mean within the occurrence' (Ahari \& Sattarzadeh, 2017). Pelanggan di kedai kopi Sequence biasanya justru lebih banyak memperlakukan kedai kopi sebagai rumah kedua mereka, dimana mereka dapat bergerak bebas dan tanpa batas-batas norma yang jelas. Hal itu dikomunikasikan lewat bagaimana mereka berperilaku dalam kedai. Walau batas-batas ruang spasial telah dikukuhkan lewat desain interior, hal itu tidak seberapa dipedulikan oleh pelanggan. Seringkali dalam kedai kopi Sequence barista yang menjaga kedai telah menjadi teman antara mereka. Hal ini penting untuk membangun rasa kepemilikan pelanggan dalam ruang spasial. 'Although there may be physical attachment to a particular place, attachment to the staff and patrons is also an essential part of what binds a person to a place' (Waxman, 2004) 
Desain interior Sequence sendiri juga dihiasi oleh berbagai pernak-pernik vintage ini. Diantaranya adalah hiasan piring lama, televisi abad 19, telepon putar, hingga poster-poster film lama yang ditempelkan ke kaca sebagai penutup. Kesan vintage tentunya akan dirasakan oleh pengunjung kedai. Tata desain seperti ini terbukti dapat memberikan stimulus nostalgia dan mempengaruhi kegiatan pembelian kepada pelanggan. Hasil penelitian oleh Rahma, Wardono, dan Budiarti menjelaskan bahwa pengalaman nostalgia positif dan disukai oleh pelanggan adalah Furnitur, elemen interior pembentuk ruang serta dan elemen dekoratif (Rahma et al., 2017). Di dalam kedai kopi Sequence sendiri terdapat banyak furnitur pelengkap dan desain interior pembentuk ruang yang mengambil tema vintage. Penempatan desain interior dan furnitur ini dapat kita ambil sebagai expressive sign dari pemilik kedai atas identitas mereka sebagai kedai kopi spesialti dengan tema vintage. Lewat analisa diatas, hal itu menjelaskan mengapa kedai Sequence termasuk kedai kopi yang banyak didatangi oleh kaum lansia selain anak-anak muda pula.

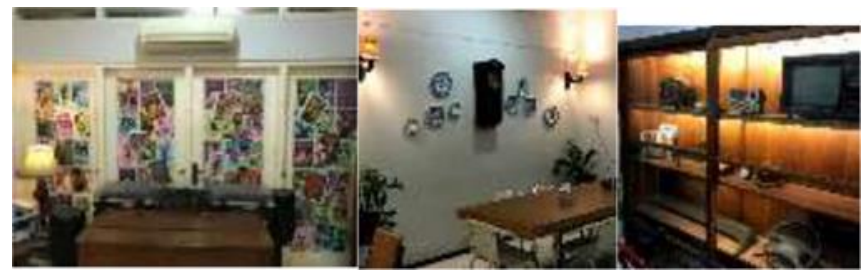

Sumber: Dokumen Pribadi Penulis

\section{Gambar 7. Interior Vintage dalam Kedai Kopi Sequence}

Rasa nostalgia ini juga memicu beberapa pekerja kantor yang datang ke Sequence untuk meluangkan waktu istirahat mereka, dikarenakan faktor kedekatan atau (proximity) dari tempat mereka bekerja (second place). Sense of place atau place attachment sendiri seringkali dikaitkan oleh tempat tinggal atau residential place (Hay, 1998, h. 7). Hal ini mengungakapkan bahwa faktor kedekatan (proximity) dan alasan geografis lainnya seringkali menanggalkan pemaknaan subjektif dari para pelanggan. Lokasi kedai ini juga berada di dalam perumahan elite yang cenderung dihuni banyak pengusaha rumahan dan juga hadir berbagai pedagang kaki lima. Hal ini memperlihatkan wilayah perkotaan yang seringkali meleburkan tempat tinggal dengan tempat kerja istilah lainnya adalah gentrification. Lewat sini, pendapat Krase dan Shortell mengenai kota sebagai contested terrain juga menjadi signifikan (Krase \& Shortell, 2011). Kebijakan tata ruang kota mencoba melakukan perubahan lokasi tempat tinggal dan kerja

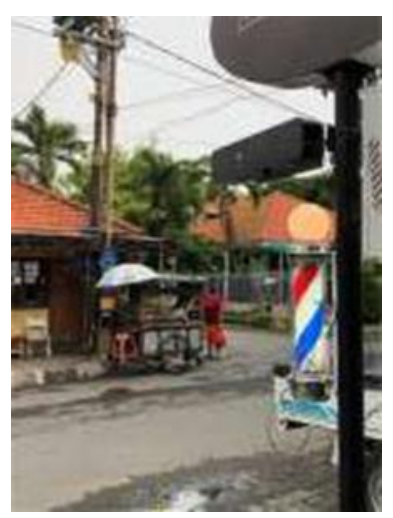


Sumber: Dokumen Pribadi Penulis

\section{Gambar 8. Potret Pedagang Kaki Lima di Sekitar Sequence}

Kedai kopi Sequence yang mempunyai slogan 'Slow Lazy Bar' dan 'We Brew Specialty Coffee' merupakan tanda bahwa kedai kopi ini memperlihatkan identitasnya sebagai kedai kopi gelombang ketiga. Pelanggan yang datang banyak yang muncul dari kalangan anak muda hingga orang tua sekalipun. Keduanya punya motivasi yang beragam untuk datang ke kedai kopi. Pelanggan setia dari kedai kopi ini juga merupakan peleburan dari kedua demografi umur pelanggan. Anak muda seringkali memperlihatkan ikatan erat mereka dengan kedai lewat aktivitas mereka yang memperlakukan ruang seperti rumah mereka sendiri. Sementara untuk pelanggan yang jauh lebih berumur memperlihatkan efek nostalgia sebagai salah satu faktor yang membuat mereka betah berlama-lama.

\section{Kedai Kopi Rumah Rendjana: Memorizing Ottoman Empire}

Rumah Rendjana terletak di Jl. Bratang Binangun I Nomor 38, Baratajaya, Kec. Gubeng, Surabaya. Hampir sama dengan Sequence. Rumah Rendjana juga terletak di kawasan tengah kota yang mempunyai pelanggan dengan berbagai macam latar belakang. Unsur pembeda yang signifikan adalah pelanggan Rumah Rendjana cenderung setia terhadap pilihan kedai kopi mereka. Bila diamati, pelanggan Rumah Rendjana seluruhnya mempunyai keinginan untuk berkumpul dalam satu tempat yang sama. Hal ini tentunya didasari dari tekanan kelompok sosial mereka untuk meluangkan waktu ke kedai kopi dan juga keberadaan komunitas di dalam kedai kopi. Rumah Rendjana membawa kebaruan diantara kedai kopi gelombang ketiga lainnya.

Rumah Rendjana membawa kebaruan diantara kedai kopi gelombang ketiga lainnya. Mereka mengusung tema kopi khas turki, namun tetap menjaga identitas mereka sebagai kedai kopi gelombang ketiga. Menurut sejarah sendiri, kopi turki merupakan olahan pertama kopi yang dikomersilkan dan disebar ke penjuru dunia. Sebelumnya, negara Turki masih disebut sebagai Ottoman Empire hingga akhirnya oleh negara-negara Eropa Barat mengenalnya dengan nama Turki/Turkish (Kucukkomurler \& Özgen, 2009).

Nama kopi Turki sendiri tidaklah merujuk pada tanah tempat tumbuhan kopi itu tumbuh. Melainkan, mengacu pada olahan kopi itu sendiri. Menurut Desem dalam (Kucukkomurler \& Özgen, 2009). Kopi Turki kemudian dimasak dalam wadah atau cezve atau gu um kemudian wadah kecil itu dimasukkan gilingan serbuk kopi dan dipanaskan diatas kompor yang diisi tanah. Tidak seperti dua kedai lainnya, Rumah Rendjana tidak menyaring sajian kopi Turki mereka, sama halnya dengan kopi tubruk khas Indonesia. Kopi tubruk khas Indonesia sendiri dilakukan dengan menyeduh air panas ke bubuk kopi dan disajikan dengan atau tanpa gula. Sebelum diminum, kopi tubruk harus dibiarkan terlebih dahulu agar ampas kopi sepenuhnya mengendap sempurna (Asiah et al., 2017). 


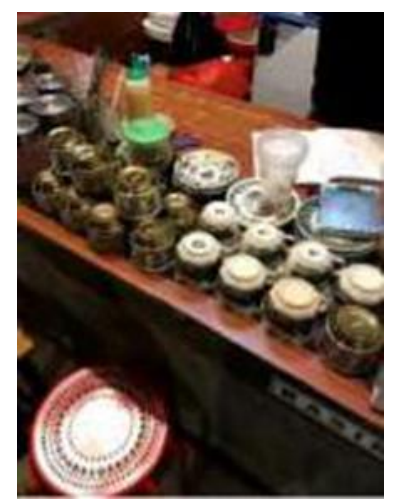

Sumber: Dokumen Pribadi Penulis

Gambar 9. Alat-alat Seduh kedai Kopi dan Suasana Kumpul Komunitas di Rumah Rendjana

Suasana di kedai kopi Rumah Rendjana mengadaptasi rumah lama di Surabaya. Tepatnya di daerah ngagel yang bersebrangan dengan Sequence. Rumah Rendjana hadir di lokasi yang jauh lebih komunal dan melebur dengan hunian masyarakat. Rumah Rendjana berdiri dengan merenovasi bangunan rumah lama menjadi kedai kopi. Secara garis besar, desain ruang di rumah rendjana tidak menghilangkan bangunan aslinya. Rumah Rendjana hanya mendobrak sekat-sekat rumah agar terasa lebih luas. Dipadupadankan dengan pernak-pernik desain khas jawa yang banyak menggunakan material kayu, ornamen bunga, hingga kursi santai khas desain rumah lama di Surabaya. Rumah Rendjana juga memberikan beberapa lapisan semen pada dinding dan lantai sebagai pengganti ubin rumah bangunan sebelumnya. Hal ini juga untuk memberikan kesan industrial dalam desain kedai namun masih bersandingan dengan pernak-pernik jawa lainnya. Hal itu juga melatar belakangi penamaan kedai ini dengan kata "rumah".

Desain yang komunal tidak lepas lewat dimana letak kedai kopi ini berada. Karena berada di kawasan hunian penduduk yang cenderung lebih berhimpit, aktivitas disekitar kedai kopi juga diisi oleh berbagai kalangan masyarakat khususnya didaerah kampong sekitar kedai. Aktivitas seperti ibadah di masjid, pedagang kaki lima yang lewat, hingga warung kopi juga terlihat di sekitar kedai.

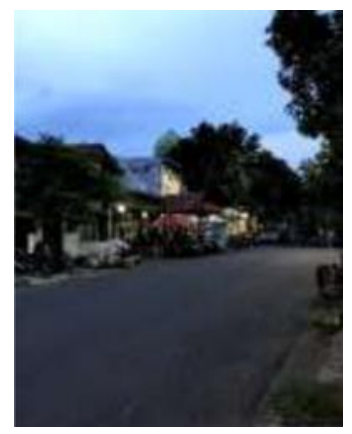

Sumber: Dokumen Pribadi Penulis

Gambar 10. Warung Kopi di Sebrang Rumah Rendjana 
Berbeda dengan bagaimana aktivitas di dalam kedai yang justru terlihat lebih ekslusif. Dianggap ekslusif karna pelanggan Rumah Rendjana jarang sekali dihadiri oleh warga sekitarnya. Walaupun secara desain arsitektur dan interior membaur dengan desain rumah sekitar. Perbedaan kelas juga terasa disini. Gaya hidup perkotaan menjadikan seseorang mempunyai konsumsi kapital yang berbeda Masyarakat perkotaan yang menyukai perbaruan dan hal unik menjadi alasan mengapa keberadaan kopi turki di Rumah Rendjana cukup diminati (Mutohharoh, 2013).

Komunitas-komunitas yang melakukan interaksi dalam ruang Rumah Rendjana secara tidak langsung memberikan makna bahwa kedai kopi ini jauh lebih komunal walaupun masih dalam konteks perkotaan. Kedai kopi Rumah Rendjana sendiri menawarkan desain yang dapat memfasilitasi berkumpulnya komunitas serta interaksi yang akrab antar anggota-anggotanya. Desain ruang yang demikian adalah usaha untuk menggabungkan elemen rural (desa) dengan elemen kota yang jauh lebih modern. Kehadiran Rumah Rendjana ditengah pemukiman penduduk adalah bukti bahwa perkotaan di Surabaya adalah gabungan dari dikotomi masyarakat desa dan kota. Rumah Rendjana hadir sebagai "third place" yang memfasilitasi siapapun untuk berkumpul tanpa ada ikatan yang formal. Penggabungan elemen ini sesungguhnya sudah dikaji lama yang ada dalam studi tentang wilayah perkotaan. Studi oleh Ebenezer Howard 'Howard's vision of a model urban community went beyond the rural-urban dichotomy and advocated the possibility of a third type of settlement that combined the attractions of the city (jobs, high wages and social opportunity) with the sunshine, fresh air and 'natural' environments of the country' (Stevenson, 2003, h. 23).

Seluruh kegiatan komunitas berada dalam ruang spasial kedai kopi yang juga mengukuhkan identitasnya lewat berbagai tanda. Sebagai salah satu kedai kopi dengan tema turki, Rumah Rendjana juga ingin memperlihatkan keunikan mereka lewat slogan dan logo yang mereka miliki.

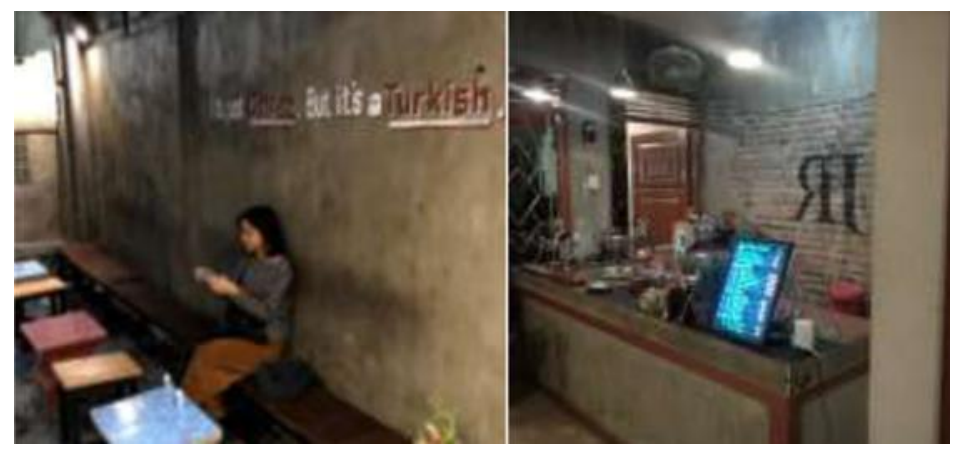

Sumber: Dokumen Pribadi Penulis

Gambar 11. Logo dan Slogan Kedai Kopi Rumah Rendjana

Kedai kopi Rumah Rendjana meletakkan berbagai logo serta tanda ekspresif disekitar kedai. Hal ini berguna untuk mengkomunikasikan identitas mereka sebagai satu-satunya kedai kopi turki di Surabaya. Keinginan mereka untuk terlihat unik dapat ditelaah lewat slogan 'it's just coffee, but it's a turkish' yang menunjukkan siapa diri mereka. Slogan diletakkan di tengah-tengah kedai dan persis dibawah tempat duduk pelanggan. Desain kedai kopi dibuat seakan terlihat luas 
dan memusat pada satu lingkaran. Sehingga wajar bila banyak komunitas yang memanfaatkan ruang-ruang di Rumah Rendjana sebagai tempat mereka berkumpul.

Komunitas kemudian membangun sense of community lewat pemanfaatannya didalam ruang spasial. Menurut (Chavis \& Wandersman, 1990) Sense of community sendiri adalah: ' $a$ phrase commonly used by citizens, politicians, and social scientist, to characterize the relationship between the individual and the social structure'. Artinya tiap individu dalam komunitas yang berada di Rumah Rendjana akan merasa sebagai bagian dari komunitas dengan cara merespon struktur sosial tempat komunitas itu berada. Sejalan dengan itu, kata komunitas juga mengindikasikan aktivitas berkumpul atau berserikat dengan dasar kebutuhan yang sama, dan keinginan yang sama. Untuk mengembangkan komunitas, dibutuhkan pula interaksi antar anggota yang ada didalam kedai kopi Rumah Rendjana. Dikotomi tentang komunitas biasanya dikukuhkan lewat bagaimana mereka memanfaatkan ruang dalam mengkomunikasikan diri mereka. Krase dan Shortell menjelaskan ini sebagai salah satu tanda phatic. Hal ini kemudian bertentangan dengan anggapan komunitas di era post modern. Artinya, tanda phatic yang diciptakan dalam kedai kopi Rumah Rendjana tidak lagi mengkomunikasikan bagaimana komunitas tersebut memanfaatkan ruang dan bagaimana mereka membedakan diri. Melainkan tanda phatic dalam kedai kopi harus dibaca sebagai indikator bahwa komunitas masih ada dalam skala masyarakat kota yang notabene sadar akan keberdaan fourth place. Hal itu diamini pula dalam tanda phatic dimana komunitas berkumpul di Rumah Rendjana dan duduk dalam lingkaran serta berinteraksi, tapi pada saat yang sama mereka juga sibuk menggunakan gawainya dan melakukan interaksi dengan 'komunitas' di dunia maya mereka. Secara aktif, komunitas ini berkumpul karena agenda akan kesamaan rasa, kebutuhan, serta keinginan mereka dalam mengukuhkan identitas komunitas mereka.

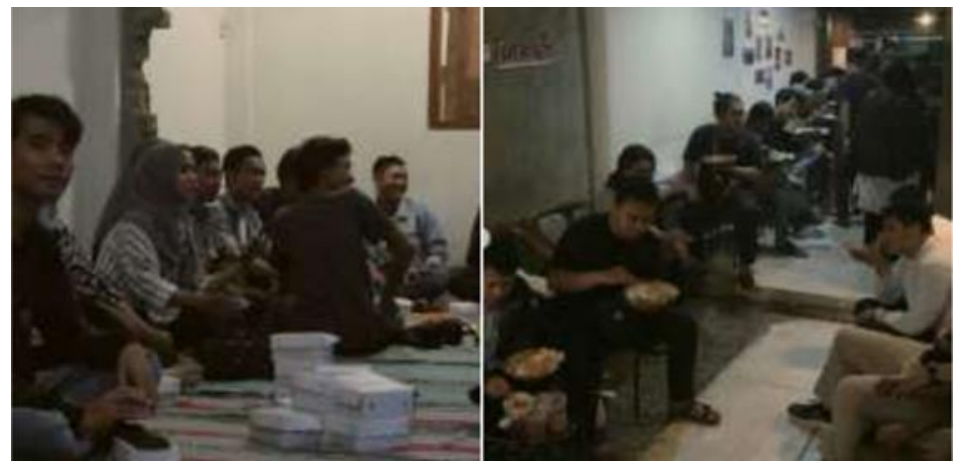

Sumber: Dokumen Pribadi Penulis

\section{Gambar 12. Komunitas Kampus ITS Buka Bersama di Rumah Rendjana}

Acara komunal oleh komunitas seperti ini, sering terjadi di Rumah Rendjana. Hal ini akhirnya memperkuat Rumah Rendjana sebagai salah satu third place. Namun, seperti yang dijelaskan diatas keanggotaan komunitas perlu dipertanyakan karena keberadaan fourth place yang mengaburkan batas antara in-group serta out group. Namun, aktivitas yang demikian tetap membangun sense of community dalam ruang spasial. 'Community refers not to relationships which people choose, but to attachments which they discover.' (Silk, 1999, h. 6). Dengan logika yang sama, keberadaan fourth place tidak akan pernah menggantikan kepuasaan yang didapat lewat komunikasi tatap muka dalam ruang spasial (third place). Dalam kedai kopi sendiri, 
komunitas yang hadir bukan berdasarkan atas keinginan mereka untuk memperbaiki lingkungan disekitar kedai kopi. Melainkan lingkungan yang direspon ada dalam skala lebih besar. Posterposter acara kajian soal perempuan, komunitas anak muda yang membahas keadilan sosial dan lain-lain juga hadir di Rumah Rendjana. Artinya, mereka juga merespon hal-hal yang ada diluar lingkungan kedai kopi itu sendiri.

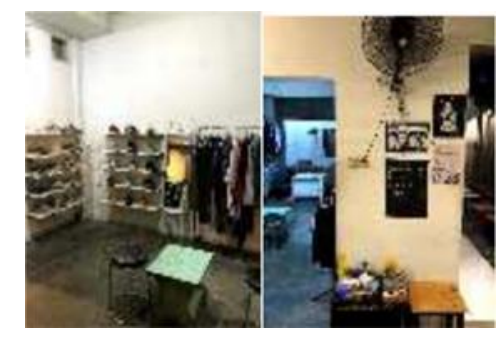

Sumber: Dokumen Pribadi Penulis

Gambar 13. Tanda Ekspresif Komunitas Radio dan Toko Baju di Kedai Kopi Rumah Rendjana

Rumah Rendjana menjadi kedai kopi yang berhasil membawa budaya komunal ke ranah kedai kopi gelombang ketiga. Hal itu dikukuhkan lewat berbagai tanda visual ruang dan juga interaksi pelanggan yang ada di dalamnya. Secara aktif, pelanggan yang didominasi oleh barisan komunitas datang dan memanfaatkan ruang kedai sebagai tempat mereka berkumpul dan mengukuhkan diri. Interaksi yang hadir di kedai kopi dapat dibilang cukup hangat. Mengingat anggota komunitas sendiri sudah saling mengenal satu sama lain sebelumnya, juga tujuan yang sama antar tiap anggota yang dinaungi oleh komunitas. Interaksi ini hadir dalam ruang kedai kopi yang mendukung terjadinya komunikasi antar anggota secara komunal. Ruang dalam kedai dibuat terbuka dan tanpa sekat yang cukup banyak, kursi panjang hingga alas untuk duduk melingkar bersama-sama. Aktivitas ini hadir dalam konteks perkotaan yang juga berarti anggota-anggota dalam komunitas adalah masyarakat kota. Masyarakat kota tentunya mempunyai akses pada social capital, economic capital hingga cultural capital. Akses ini memungkinkan mereka untuk menyukai hal-hal bersifat baru dan unik seperti kopi khas turki untuk kemudian diadaptasi maknanya demi mengukuhkan identitas mereka.

\section{PENUTUP}

Gaya hidup urban kedai kopi gelombang ketiga termasuk dalam third place yaitu ruang dimana setiap individu dapat berinteraksi tanpa paksaan dan cenderung memanfaatkan waktu luang atau leisure. Disini para pelanggan yang juga termasuk masyarakat kota sering menghabiskan waktunya untuk apapun yang mereka kehendaki. Tujuan pelanggan datang juga bermacam-macam mulai dari berkumpul bersama kerabat dan teman hingga ke aktivitas serius seperti mengerjakan tugas dan rapat. Seluruh aktivitas pelanggan dalam ruang spasial kedai kopi kemudian dapat menjelaskan gaya hidup urban khas Surabaya. Ruang kedai kopi serta pelanggan didalamnya adalah visual text yang penuh dengan pemaknaan. Makna tersebut dapat muncul dengan melihat bagaimana pelanggan memanfaatkan ruang kedai dan kedai kopi menyusun ruang tersebut. Hal itu dapat dibaca lewat tanda visual yang ada di dalam kedai, khususnya tanda expressive dan phatic.

Ketiga kedai kopi mempunyai perbedaan pola arsitektur dan perilaku pelanggan. Sebagai kedai kopi gelombang ketiga, seluruh kedai kopi mempunyai tanda expressive khas yang sama. 
Yaitu letak bar yang ditaruh didepan agar semua pelanggan dapat melihat proses kopi diolah. Kedai pertama, Start with Coffee adalah kedai kopi yang baik ruang dan perilaku pelangannya mendukung aktivitas akademis. Disediakan berbagai kursi panjang serta meja lebar hingga kebutuhan colokan listrik juga dipenuhi untuk para pelanggannya yang mayoritas akademisi agar merasa nyaman. Kenyamanan ditambah dengan desain kedai yang mengusung tema Bohemian. Tanda visual expressive terlihat lewat penataan meja, lokasi bar, pakaian mahasiswa, hingga logo kedai kopi itu sendiri. Sementara tanda phatic dapat dilihat lewat interaksi pelanggan satu sama lain serta cara mereka memanfaatkan ruang kedai. Kedai kopi ini mencerminkan budaya urban masyarakat kota khususnya di kalangan anak muda atau mahasiswa. Sesuai dengan pemahaman bahwa perkotaan jauh lebih modern, para mahasiswa berdiskusi menggunakan gawai telepon genggam hingga laptop, mereka juga memanfaatkan teknologi $e$-wallet untuk melakukan pembayaran. Tanda visual ini juga mengindikasikan ada identitas kelas yang dibangun di dalam kedai kopi dan memisahkan antara pelanggan Start with Coffee dan yang bukan. Pelanggan dalam Start with Coffee khas dengan cara mereka berpakaian yang rapi, menggunakan gawai laptop atau handphone, serta membawa banyak buku akademis dan paham akan cita rasa kopi spesialti.

Kedai kopi kedua adalah, Sequence. Kedai kopi ini terletak di daerah Ngangel, Surabaya yang dikelilingi oleh perkantoran dan pemukiman penduduk menengah ke atas. Karena itu, mayoritas pelanggan datang pada jam istirahat makan siang yang didominasi oleh pelanggan kantoran dan juga. Sementara pada malam hari, kedai kopi justru didominasi oleh pelanggan anak muda yang bahkan tetap berkumpul di lokasi hingga tutup. Secara desain, Sequence mengambil tema vintage yang memadupadakan beberapa furnitur dan pernak-pernik barang antik didalam kedai kopi sebagai tanda expressive. Hal ini memicu efek nostalgia yang hadir dalam pelanggan, khususnya pada pelanggan kantoran yang sudah berumur. Ketika melihat hiasan vintage mereka akan menggali kembali ingatan mereka pada masa lalu. Lokasi kedai ini bertumpuk dengan bisnis lainnya yang menjadi tanda visual phatic khas perkotaan. Bisnis lainnya adalah restoran dengan nama Retro Teras Kuliner dan juga tempat potong rambut. Letak bisnis yang berlokasi pada satu ruang dapat terlihat diseluruh penjuru kota, khususnya Surabaya.

Terakhir adalah kedai kopi Rumah Rendjana yang berlokasi tidak jauh dari Sequence. Keunikan utama kedai ini adalah mengusung tema kopi khas turki dan menggunakan alat-alat tradisional ala turki pula. Kedai kopi berusaha menjual identitas ini kepada para pelanggan. Hal itu terlihat lewat slogan mereka yaitu "it's just a coffee, but it's a Turkish". Slogan dilukis pada dinding kedai sebagai tanda expressive dari identitas mereka. Walau mempunyai tema sendiri, kedai kopi ini masih termasuk dalam kedai kopi gelombang ketiga. Terlihat dari lokasi bar yang terbuka serta biji kopi spesialti yang mereka gunakan. Di sini kedai kopi menggunakan desain yang jauh lebih komunal dari kedai kopi sebelumnya. Lokasi kedai berada di pemukiman yang rata-rata berekonomi rendah. Hal ini menjadikan suasana sekitar kedai terlihat lebih ramai dan banyak aktivitas. Desain Rumah Rendjana sendiri adalah hasil renovasi rumah lama yang kemudian diubah menjadi kedai kopi. Di sini, ruang kedai kopi merupakan susunan dari berbagai meja panjang yang hampir seluruhnya menghadap memusat ke tengah. Hal ini merupaka tanda expressive yang berusaha dibangun kedai agar tiap pelangannya dapat berinteraksi satu sama lain dengan lebih intim walau tidak saling kenal.

Hal itu diamini pula dengan tanda phatic dari interaksi pelangannya yang mayoritas berasal dari jaringan komunitas. Seringkali anggota komunitas kajian feminisme, anggota HIMA kampus hingga beberapa diskusi kritis terjadi dalam Rumah Rendjana. Hal ini dapat terjadi karena lokasi 
yang mendukung untuk berdiskusi dengan baik. Komunitas yang hadir di Rumah Rendjana juga meninggalkan berbagai tanda expressive mereka disudut-sudut kedai yang berupa poster acara. Desain rumah pada kedai ini terlihat jelas lewat susunan bata merah dan tembok semen yang mereka gunakan agar tidak menghilangkan identitas rumah, maka penamaan Rumah Rendjana menjadi masuk akal. Akibatnya desain ruang kedai tidak terlalu mencolok dibandingkan dengan bangunan di lingkungannya. Diamini pula dengan tanda phatic dari interaksi pelangannya yang mayoritas berasal dari jaringan komunitas. Seringkali anggota komunitas kajian feminisme, anggota HIMA kampus hingga beberapa diskusi kritis terjadi dalam Rumah Rendjana. Hal ini dapat terjadi karena lokasi yang mendukung untuk berdiskusi dengan baik. Komunitas yang hadir di Rumah Rendjana juga meninggalkan berbagai tanda expressive mereka disudut-sudut kedai yang berupa poster acara.

Dari ketiga kedai kopi tersebut dapat disimpulkan bahwa gaya hidup urban khas masyarakat Surabaya dapat dilihat lewat aktivitas mereka di kedai kopi. Sesuai dengan (Mutohharoh, 2013) masyarakat urban adalah yang suka akan kebaruan dan praktis. Namun, konsumsi kopi di kedi gelombang ketiga kemudian mempunyai makna sendiri bagi masyarakat kota. Makna ini mengenai bagaimana aktivitas meminum kopi adalah pertarungan makna dari tiap gelombang tempat yang menyediakannya atau contested terrain (Krase \& Shortell, 2011). Kontes yang dimaksud adalah tentang hegemoni budaya meminum kopi yang selalu diperdebatkan maknanya di tiap gelombang lewat tanda visual phatic dan expressive di wilayah perkotaan. Pada gelombang pertama, produksi massal kopi instan dirasa paling tepat dimana kopi identik dengan perjamuan di tiap rumah orang atau warung kecil di jalanan. Gelombang kedua kemudian melawannya dengan memproduksi ruang yang lebih besar lengkap dengan fasilitas teknologi yang lebih memadai. Lalu pada gelombang ketiga, kita disuguhkan dengan pengolahan serta pengetahuan biji kopi yang jauh lebih kritis dan detil. Dari ketiga gelombang tersebut semuanya sama-sama mencoba merubah makna tentang meminum kopi.

Kekhasan pada kedai kopi gelombang ketiga adalah tentang kaburnya makna meminum kopi itu sendiri pada tiap kedai. Dari ketiga kedai kopi tersebut dapat dirangkum bahwa pada gelombang ketiga ruang kedai kopi masih menjadi third place dalam konteks urban perkotaan. Kedai kopi menjadi tempat untuk berdiskusi serius secara kolektif hingga tempat bersantai untuk menghabiskan waktu luang. Tiap-tiap pelanggan disuguhkan dengan nilai-nilai baru hasil dari adaptasi tanda visual phatic pada kelas ekonomi bawah dan berubah menjadi tanda expressive bagi para pelanggan. Desain lantai semen dan dinding beton di Rumah Rendjana, Desain bohemian pada interior Start with Coffee, hingga rasa nostalgia yang dibangun lewat furniture jaman dulu di Sequence adalah contoh dari adaptasi tanda phatic ekonomi kelas bawah kedalam expressive pelanggan kedai. Tanda expressive ini kemudian digunakan pelanggan serta kedai kopi untuk mengukuhkan identitas mereka sebagai masyarakat kota yang suka akan kebaruan serta hal-hal unik. Masyarakat kota dengan konsumsi kapitalnya kemudian mampu membangun makna-makna tertentu dari aktivitas meminum kopi. Suatu ruang dirancang untuk dapat memenuhi kebutuhan para penghuninya. Aktivitas meminum kopi di warung pinggir jalan adalah bukti bahwa meminum kopi menjadi kebutuhan tiap orang, sehingga keberadaannya ada dimana-mana. Lain halnya pada era post-modern di wilayah perkotaan. Kedai kopi gelombang ketiga menjawab kebutuhan masyarakat kota yang gemar mengonsumsi makna-makna tertentu dari aktivitas meminum kopi. Bahwa meminum kopi tidak hanya melibatkan kebutuhan dosis kafein belaka, melainkan adalah kegiatan psikis yang mengukuhkan identitas individu atau kelompok didalamnya. Lewat ruang 
visual kedai kopi tidak hanya mencitrakan bahwa kedai kopi mereka unik, tetapi pelanggan yang datang akan merasa bahwa mereka juga termasuk dalam golongan tertentu yang tidak dapat disamakan dengan individu/kelompok lainnya. Perasaan ini juga membawa pada kesimpulan bahwa yang dikonsumsi oleh pelanggan adalah kesan dan makna dalam ruang kedai kopi lewat tanda visual. Hal ini khas dengan masyarakat urban dan gaya hidup post-modern. Konsep kedai kopi third wave yang kritis terhadap olahan kopi tidak diindahkan oleh para pengunjung. Justru, pengujung ingin terlihat seakan-akan peduli terhadap olahan kopi dengan datang ke kedai kopi tersebut. Hal ini tentunya sangat erat dengan gaya hidup post-modern yang seringkali menyimbolkan barang-barang consumer goods yang punya makna lebih kepada individu atas dirinya ataupun golongan kelompok apa dia berasal.

\section{DAFTAR PUSTAKA}

Ahari, A. S., \& Sattarzadeh, D. (2017). "Third Place", A Place for Leisure Time and its Relationship with Different Social Setting in Tabriz, Iran. Int. J. Architect. Eng. Urban Plan, 27(2), 95-105. https://doi.org/10.22068/ijaup.27.2.95

Asiah, N., Septiyana, F., Saptono, U., Cempaka, L., \& Sari, D. A. (2017). Identifikasi Cita Rasa Sajian Tubruk Kopi Robusta Cibulao Pada Berbagai Suhu Dan Tingkat Kehalusan Penyeduhan. Barometer, 2(2), 52-56.

Chavis, D. M., \& Wandersman, A. (1999). Sense of Community in the Urban Environment: A Catalyst for Participation and Community Development. A Quarter Century of Community Psychology, 18(1), 265-292.

Eleonora, L. (2017). Bangkitnya Semangat Kopi Specialty di Kota Pahlawan. Kopikini., diakses 18 Januari 2020, dari http://kopikini.com/bangkitnya-semangat-kopi-specialty-di-kotapahlawan/

Hay, R. (1998). ENVIRONMENTAL PSYCHOLOGY SENSE OF PLACE IN DEVELOPMENTAL CONTEXT Journalof. Journal of Environmental Psychology, 18(January 1998), 5-29.

Hindrawan. (2018). Gerai Gelombang Ketiga. Tempo Media Grup, 65-67. diakses 18 Januari 2020, dari https://investigasi.tempo.co/edisi-khusus-kopi/gerai-gelombang-ketiga/index.html

Ida, R. (2014). Metode Penelitian: Studi Media dan Kajian Budaya. Prenada Media.

Krase, J., \& Shortell, T. (2011). On the spatial semiotics of vernacular landscapes in global cities. Visual Communication, 10(3), 371-376. https://doi.org/10.1177/1470357211408821

Krase, J., \& Shortell, T. (2013). On the Visual Semiotics of Collective Identity in Urban Vernacular Spaces., dalam R. Nathansohn, \& D. Zuev (Eds.), Sociology of The Visual Sphere (Vol. 1, p. 204). New York: Routledge.

Kucukkomurler, S., \& Özgen, L. (2009). Coffee and Turkish coffee culture. Pakistan Journal of Nutrition, 8(10), 1693-1700.

Mutohharoh, A. (2013). Budaya Urban. http://aliyahmuthoharohfib09.web.unair.ac.id/artikel_detail-70801-Umum-BUDAYA URBAN.html 
Olsen, N. L. (2013). Caffeine Consumption Habits and Perceptions among University of New Hampshire Students. Honors Theses and Capstones and Capstones, 103.

Öztürk, E., Yilmazer, S., \& Ural, S. E. (2012). The effects of achromatic and chromatic color schemes on participants' task performance in and appraisals of an office environment. Color Research and Application, 37(5), 359-366.

Rahma, M. S., Wardono, P., \& Budiarti, L. N. (2017). Pengaruh Elemen Interior Restoran Terhadap Pengalaman Nostalgia Konsumen. Journal of Visual Art and Design, 9(2), 67.

Silk, A. J. (1999). The Dynamics of Community, Place, and Identity. International Journal of Engine Research, 6(4), 5-17. Stevenson, D. (2003). Cities and Urban Cultures. Open University Press.

Stevenson, D. (2003). Cities and Urban Cultures. Philadelphia: Open University Press.

Waxman, L. K. (2004). More than coffee: An examination of people, place, and community with implications for design. ProQuest Dissertations and Theses, December, 309-309 p. 